\title{
FUNÇÃO DE ALTERIDADE: O CANGUME, A \\ PROFESSORA, A ESCOLA E A UNIVERSIDADE
}

\author{
José Maurício Arruti (UNICAMP)*
}

\begin{abstract}
RESUMO
Este texto investiga, por meio de uma pequena série de situações históricas e cenas etnográficas, a construção e a ressignificação da fronteira simbólica que marca a distância e a proximidade entre a comunidade quilombola do Cangume (Itaóca SP) e a sociedade branca do seu entorno. Neste relato, que cobre desde a década de 1970 até o momento presente, ganha destaque o papel desempenhado por agentes, saberes e práticas escolares. Posto de observação, marcador da distância ou agência de aproximação, a escola serviu como espaço de reelaboração simbólica da fronteira cujos conteúdos e sentidos foram sendo alterados ao longo do tempo. Nosso objetivo é chamar atenção para a "função de alteridade" desempenhada por esta fronteira, iluminando com o caso do Cangume um dispositivo comum e mais geral que marca a relação entre outras comunidades quilombolas e as populações do seu entorno e, em especial, com a escola.
\end{abstract}

Palavras-chave: Racismo. Caridade. Política. Linguística. Africanismos.

\begin{abstract}
ALTERITY FUNCTION: THE CANGUME, THE TEACHER, THE SCHOOL AND THE UNIVERSITY

This text brings together historical and ethnographic scenes to describe the construction and resignification of the symbolic border that marks the distance and proximity between the quilombola community of Cangume (Itaca - SP) and the white society of its surroundings. In this story, which covers the 1970s to the present, the role played by agents, knowledge and school practices is highlighted: the school served as a space to reelaboration the symbolic contents and senses of the border. Our objective is to draw attention to the 'alterity function' of this border, illuminating with the case of Cangume a common and more general device that marks the relationship between other quilombola communities and the populations of their surroundings, and especially with the school.
\end{abstract}

Keywords: Racism. Charity. Politics. Linguistic. Africanisms.

\section{RESUMEN}

FUNCIÓN DE ALTERIDAD: EL CANGUME, LA PROFESORA, LA ESCUELA Y LA UNIVERSIDAD

* Professor do Departamento de Antropologia da Universidade Estadual de Campinas (Unicamp). Doutor e Mestre em Antropologia Social pelo Museu Nacional - Universidade Federal do Rio de Janeiro (UFRJ). Graduado em História pela Universidade Federal Fluminense (UFF). Pesquisador do Centro de Pesquisa em Etnologia Indígena (CPEI/Unicamp) e do Centro de Estudos Rurais (CERES/Unicamp), onde coordena o Laboratório de Pesquisa e Extensão com Povos Tradicionais Afro-americanos (LAPA). E-mail:jmarruti@gmail.com 
Este texto reúne escenas históricas y etnográficas para describir la construcción y la resignificación de la frontera simbólica que marca la distancia y la proximidad entre la comunidad quilombola del Cangume (Itaóca - SP) y la sociedad blanca de su entorno. En este relato, que cubre la década de 1970 hasta el momento presente, se destaca el papel desempeñado por agentes, saberes y prácticas escolares. La escuela sirvió como espacio de reelaboración una simbólica de la frontera cuyos contenidos y sentidos se fueron alterando a lo largo del tiempo. Nuestro objetivo es llamar la atención sobre la 'función de alteridad' de esta frontera, iluminando con el caso del Cangume un dispositivo común y más general que marca la relación entre otras comunidades quilombolas y las poblaciones de su entorno y, en especial, con la escuela.

Palabras clave: Racismo. Caridad. Política. Lingüística. Africanismos.

\section{Apresentação}

"Cangume" é o nome de um bairro rural do município de Itaóca, Vale do Ribeira, quase na fronteira do estado de São Paulo com o Paraná. Quando realisei os estudos para o reconhecimento do bairro como comunidade remanescente de quilombos em $2003,{ }^{1}$ ele era formado por 37 famílias negras, que somavam cerca de 150 moradores permanentes, todos descendentes de três troncos principais, os Monteiro, os Gonçalves e os Maciel de Pontes, que se misturavam em uma intrincada rede de parentesco, por meio do constante casamento entre primos. Os moradores do bairro viviam sobre uma terra de uso comum de aproximadamente 37 hectares, conhecida como "patrimônio do Cangume", localizada no fundo de um pequeno vale, onde suas famílias mantinham minúsculas hortas cercadas e a criação solta de porcos e cabras. $\mathrm{O}$ acesso ao "patrimônio do Cangume" se dava por uma precária e estreita estrada de terra, que o ligava à cidade de Itaóca. Os outros caminhos, que ligavam o bairro à cidade de Apiaí e ao município de Iporanga, haviam sido abandonados e estavam quase intransitáveis, só podendo ser cruzados a pé ou a cavalo. ${ }^{2}$ Todos, sem exceção, eram kardecistas e frequentavam o Centro

1 O estudo foi realizado em três estadias entre 2002 e 2003, que somaram cerca de 40 dias em campo. Deste trabalho de campo e das pesquisas documentais e bibliográficas complementares resultou o Relatório Técnico-Científico, realizado conforme as exigências do decreto estadual $\mathrm{n}^{\circ} 40.723 / 96$, que definia a aplicabilidade do artigo 68 do ADCT (CF/1988) em território paulista até a edição do Decreto $\mathrm{n}^{\circ} 4.887 / 2003$.

2 O caminho que levava a Iporanga, por exemplo, convertera-se em rota dos motociclistas de Rally que buscam justamente os caminhos mais difíceis e enlameados de acesso ao Parque Estadual Turístico do Alto Ribeira (PETAR).
Espírita Fé em Deus, que, fundado na década de 1930, tornou-se uma referência na região, pelo histórico de serviços de cura prestados a pessoas dos bairros e municípios vizinhos.

Tais dificuldades de acesso, a endogamia e a excepcionalidade religiosa justificavam a imagética de "isolamento" que sempre esteve associada ao bairro, ainda que tal ideia de isolamento tivesse um significado mais amplo, ganhando uma função mais simbólica que descritiva. De fato, para a população do município de Itaóca, o nome Cangume não descrevia apenas uma população e um lugar, mas funcionava como o indicador de uma fronteira (BARTH, 1976; CARDOSO DE OLIVEIRA, 1976) de grande eficácia simbólica e prática.

Os demais bairros do município eram formados, predominantemente, por descendentes das primeiras famílias proprietárias de terras e escravos que chegaram à região em busca de ouro ainda no século XVIII, aos quais se juntaram as familias de migrantes mineiros e paranaenses que chegaram à região na década de 1960 , em busca de terras baratas, em meio a um grande processo de regularização fundiária que instaurou um intenso mercado de terras no Vale do Ribeira. ${ }^{3}$ Em razão da pouca terra disponível, os moradores do Cangume trabalhavam como diaristas para os fazendeiros vizinhos, recebendo remuneração que podia ser até $50 \%$ menor que a dos trabalhadores dos outros

3 Uma descrição deste processo e dos seus efeitos sobre a comunidade do Cangume, que provavelmente repete os efeitos do mesmo processo sobre outras comunidades negras da região, está disponível no artigo decorrente do RTC (ARRUTI, 2007). 
bairros, em sua quase totalidade brancos. Esta era a manifestação mais brutal da discriminação e do racismo que recaia sobre o grupo, mesmo com o destaque que ele já alcançava como como "comunidade quilombola", reconhecida oficiosamente pelos poderes municipais. Ainda assim, a noção de racismo parece estreita para descrever a fronteira simbólica a que nos referimos e à qual eram atribuídos conteúdos variados.

O objetivo deste texto é investigar, por meio de uma pequena série de situações históricas e cenas etnográficas, a construção e a ressignificação dessa fronteira simbólica por parte da sociedade branca de Itaóca. O interesse desta descrição para a coletânea em que se insere está no fato de tais situações e cenas evidenciarem o papel que agentes, saberes e práticas escolares desempenharam na elaboração e reelaboração da imagética do quilombo, associado à noção de isolamento. A escola serviu, como se verá, como um lugar estratégico a partir do qual se produziu um discurso sobre o Cangume e sobre a fronteira simbólica que o distingue do seu entorno. Posto de observação, marcador da distância ou agência de aproximação, a escola serviu como espaço de reelaboração simbólica daquela fronteira, operando na produção daquilo que eu proponho chamar de função de alteridade para o Cangume.

Essa função de alteridade que o Cangume desempenhou ou ainda desempenha para a população de Itaóca poder servir para iluminar, talvez pelo exagero, um dispositivo comum e mais geral que marca a relação entre outras comunidades quilombolas e as populações do seu entorno. Sugiro que tal função de alteridade é fundamental para compreender tanto o caráter colonial que marca a relação que a sociedade local estabelece com as comunidades quilombolas, quanto as razões pelas quais os coletivos negros socialmente segregados, mesmo que sem adesão à noção de negritude ou sem uma memória clara de um passado de resistência à escravidão (ou mesmo de um passado escravo) podem aderir ao rótulo de "comunidades remanescentes de quilombos".

1.

O Censo Demográfico de 2010 registrou uma população de pouco mais de três mil e duzentos habitantes em Itaóca, o que coloca este município, criado em 1991 por desmembramento de Apiaí, entre os 100 menores dentre os 645 municípios do estado. Seu tamanho encontra correspondência em um PIB per capta ainda menor ( $\mathrm{R} \$ 9.676,68)$, que fica entre os 25 piores do estado. Esta situação projeta-se sobre a paisagem: em 2010, apenas $35 \%$ dos domicílios (concentrados no núcleo urbano) contavam com esgotamento sanitário e apenas $17,5 \%$ deles (o centro histórico do núcleo urbano) possuiam vias públicas com "urbanização adequada" segundo os critérios do IBGE, ou seja, com a presença de bueiro, calçada, pavimentação e meio-fio. As condições de vida dos seus moradores acompanhavam a forte concentração expressa nesta paisagem. Apenas $12 \%$ de sua população registravam ocupação formal, resutando em um rendimento mensal e em uma taxa de mortalidade infantil que ficavam entre as dez piores do estado: $47,5 \%$ dos seus domicílios possuíam rendimentos médios mensais por pessoa de até meio salário mínimo e a taxa de mortalidade infantil média era de 46,5 para 1.000 nascidos vivos. A soma desses e outros critérios situavam Itaóca entre os mais baixos índices de desenvolvimento humano do estado de São Paulo: um IDH de 0,680 para uma variação entre 0,639 e 0,862 (INSTITUTO BRASILEIRO DE GEOGRAFIA E ESTATÍSTICA, 2017).

A essa situação socioeconômica devemos acrescentar que o município não possui formas materiais ou imateriais reconhecidas de patrimônio cultural ou histórico, assim como qualquer oferta de serviços culturais regulares. Um contexto, portanto, que ainda que não seja de miséria, está no limite da pobreza e do isolamento que por muito tempo caracterizou a percepção pública sobre o Vale do Ribeira. É diante desta moldura que devemos interpretar a cena que chamou minha atenção e que podemos tomar como a mais espontânea e explícita referência à fronteira simbólica atribuída ao bairro do Cangume por parte dos moradores da cidade. Da varanda da pousada em que eu pernoitava, pude assistir uma jovem que, sentada à porta de sua casa, provocava debochadamente um grupo de rapazes que passava pela rua, perguntando se eles não iam se divertir naquela noite e se eles não iam comprar "uma boa cachaça lá no Cangume". A cena me deixou intrigado porque no Cangume não só não se 
produz cachaça, como nem mesmo se bebe bebida alcoólica, por razões religiosas. Mais tarde me foi explicado que é comum na cidade usar o Cangume como referência de piadas. Nas entediantes noites em que não têm qualquer diversão que lhes ocupe, por exemplo, os jovens brincam dizendo que vão a "um baile lá no Cangume". Ainda que o significado da brincadeira não seja evidente e imediato para os que chegam de fora, percebi que ele estava relacionado à expressão "lá no", que marca a construção das frases que me foram citadas: a expressão reifica o sentido de distância que sustenta a graça que nos escapa.

Em primeiro lugar é necessário perceber que a brincadeira está marcada por uma autoironia daqueles que reconhecem a sua própria situação de precariedade cultural e de recursos de lazer. Entretanto, este ensaio de autoironia é atenuado e quase anulado ao encontrar um ponto de fuga no Cangume. Esta parece ser a função de alteridade mais elementar desempenhada pelo bairro para os moradores brancos do município. Independentemente do conteúdo das frases que fazem referência ao Cangume, importa o fato de ele ser sempre o lugar (social e simbólico) a que se faz referência como o "lá no", isto é, o distante, o outsider, o símbolo de alteridade. Assim, a expressão "cangumeiro" assumiu para a população do município um significado amplo e impreciso, mas ao qual poderíamos nos aproximar por meio de expressões como capiau, bugre, místico, pobre, bêbado e, fundamentalmente, negro. Um cangumeiro é, em primeiro lugar, um negro, mas ao qual acrescenta-se alguma qualidade negativa próxima à de "errado", "torto" ou "primitivo". Está aí a graça: projetar permanentemente sobre um outro específico os estigmas genéricos dos quais se quer livrar. O racismo, neste contexto, parece buscar no contraste com a negritude dos corpos dos moradores do quilombo o último signo de hegemonia a que a população branca daquela cidade pode recorrer: a função de alteridade do Cangume está na reafirmação de uma branquitude ameaçada pela pobreza e pelo isolamento.

\section{2.}

A força dessa função de alteridade, imputada ao Cangume, se manifesta no fato de ela resistir até mesmo à convivência com seus moradores ou, pelo contrário, no fato de tal convivência servir para seu reforço ou, ainda, no fato de se poder tirar alguma vantagem simbólica da convivência com tal símbolo de alteridade. Isso fica evidente na pequena narrativa autobiográfica de uma ex-professora do Cangume.

Diana (pseudônimo) foi, no início dos anos 1960, a primeira professora regular designada pela prefeitura de Apiaí para o bairro. Ainda que ela fosse uma "professora leiga" e tenha sido precedida por outros e outras professoras e professores voluntários, que ministraram as primeiras letras aos seus moradores, Diana narra ter inaugurado a primeira escola do bairro e ter sido uma das primeiras pessoas a fazer contato com os pretos do Cangume. Ela teria introduzido as primeiras noções de "cultura" entre uma população de verdadeiros "bugres", que mal falavam a sua língua, segundo ela mesma conta.

Diana conta essa história ${ }^{4}$ dentro de uma outra história, que começa no dia em que, em 1988, de zeladora da escola, ela foi absorvida como professora do município de Apiaí. Relata que nessa ocasião houve certa confusão em torno da sua nomeação para a vaga, porque algumas jovens haviam sido melhor classificadas no concurso promovido pela prefeitura. Para arrefecer os ânimos e justificar sua precedência, a diretora da escola pediu que Diana contasse a sua história às professoras da escola, que a viam com desconfiança. Assim, como Sherazade, sua narrativa inicial leva à outra narrativa, que nos leva ao Cangume:

Um belo dia, estavam todas lá na sala e eu peguei e falei assim: 'Escuta vocês colegas - porque agora vocês são minhas colegas, porque eu sou professora agora, agora eu sou de verdade. Mas eu já fui professora no coração das crianças, no coração dos pais das crianças desse bairro que eu vou citar pra vocês. A primeira escola, a primeira experiência que eu tive

4 Oswaldo Mancebo (1930-2011), poeta e histotiador autodidata, generosamente me cedeu a gravação desta entrevista realizada como parte das pesquisas para a redação do seu livro de causos e memórias de Apiaí. Macebo praticava uma espécie de arqueologia de salvamento da documentação histórica do município. Em meio a um e outro incêndio, um e outro descarte administrativo que, displicentemente, vão dando fim à documentação histórica do município, este dedicado historiador local realizou a importante tarefa de transformar lixo em arquivo. Quando o conheci a professora "Diana" já havia falecido. 
em minha vida, foi em 1964, na escola do Cangume, que era um sertão. Eu... Eu abri essa escola lá, com o maior sacrifício da minha vida.

\section{$[\ldots]$}

O diretor naquele tempo, o sr. Sérgio, ele deu essa escola pra mim e perguntou pra mim: 'Dona [Diana], a senhora tem coragem de enfrentar o sertão?' Eu falei: 'É sertão?'. 'É sertão sim. Um sertão em que nunca ouviram nem falar em escola até hoje. Inclusive a senhora vai encontrar lá muitas barreiras. Porque a senhora é leiga, mas ninguém nem precisa saber que a senhora é leiga, porque a senhora pra nós é uma professora e pra eles vai ser também. Porque, se perguntar, pra essa turma de professoras que estão aí, se elas querem enfrentar essa barreira, eu tenho certeza que elas não vão enfrentar. E a senhora, por ser uma guerreira, vai.' Ainda ele falou pra mim: 'A senhora vai encontrar não só criança analfabeta, a senhora vai encontrar adultos, velhos, que nunca soube o que é pegar num lápis. A bem da verdade, a senhora vai encontrar bugres. A senhora tem coragem?'. Eu precisava trabalhar, precisava ajudar o meu marido, eu tinha filhos pequenos, mas eu ia enfrentar, sim.

Mas o sr. Sérgio disse: 'Só que a senhora tem que se preparar. A senhora tem que ter roupa própria pra entrar no sertão; a senhora tem que andar a cavalo; sozinha a senhora não pode ir, tem que ir acompanhada de uma pessoa da cidade de Itaóca - porque lá é um sertão e eu sei que nem estrada tem; e outra coisa, a senhora vai ter que usar uma arma, um revólver, qualquer coisa. Mesmo que a senhora não tenha coragem de dar tiro, a senhora tem que ir com esse revólver, porque a senhora vai enfrentar pessoas que a gente nunca viu na vida e a gente não sabe qual vai ser a reação deles quando a senhora chegar lá. Então, eles vendo a senhora igual uma valentona, de revólver na cintura, de bota, a senhora entra lá e vê o que a senhora consegue fazer'. Quinze dias depois eu estava preparadinha para ir. (DIANA).

Um relato que se aproxima do estilo heróico dos relatos sobre as investidas bandeirantes sobre os sertões selvagens, em busca de bugres arredios. $\mathrm{O}$ método de contato, se não é a violência direta do apresamento, pretende ser o da coação pela aparência, transformando em estratégia a mesma imagem que está na origem do temor que dá o sentido heróico da jornada: uma representação do desconhecido. $\mathrm{Na}$ encomenda da jornada à jovem professora leiga não há como saber se a população de que se fala é indígena ou negra, apenas que era primitiva e, por isso, de reações desconhecidas. Aliás, não parece haver qualquer descontinuidade necessária entre as ideias de "bugre" e negro neste contexto, como se vê a seguir:

Então eu desci aquela serra a cavalo [...] e quando eu fui chegando no bairro, de longe assim, que lá é um descidão, um buracão, eu vi aquelas casinhas, igual aquelas casinhas de índio mesmo, tudo de sapé. Parecia um vilarejo de índio mesmo. A primeira pessoa que eu vi foi um negrão, um pretão mesmo, daqueles de amedrontar a gente, sabe. Eu falei: 'Ai ai ai, onde é que eu vim parar?'

\section{[...]}

Depois que eu cheguei lá, levou 45 dias pra mim conseguir a matrícula das crianças, porque eles corriam. Logo que eles me viam, eles corriam. Eu batia palmas numa casa assim, e apontava uma mulherzinha na janela, depois o homem apontava também e eu chamava: 'O sr faz favor de vim aqui', e ele vinha, cabreirão comigo, e a mulher vinha atrás [...] com aquele linguajar que se for pra imitar eu nem sei, linguajar de bugre mesmo, bem caipirado. Eu dizia: 'Eu vim aqui abrir uma escola, o senhor já ouviu falar em escola? É onde coloca as crianças pra aprender a ler e a escrever, pra ter educação.' Eles diziam: 'Mas nesse bairro aqui? Aqui não tem nem lugar pra professora ficar.' 'Eu fico em qualquer lugar, o cantinho que o senhor me der aí no rancho, um colchãozinho, uma esteira que o senhor me der eu fico, porque eu vim para trabalhar.' Foram 45 dias comendo o quê? Feijão com farinha e de vez em quando uma abóbora. Eu falei ao chefe do povo pra ele ajeitar um lugar pra mim poder dar aulas pras crianças. Criança nada, que já era quase tudo adulto, com 15 ou 17 anos. Em 45 dias assim, eu consegui matricular 42 crianças. (DIANA).

Depois dessa sua primeira estadia, Diana retornou a Itaóca, onde recolheu alguns caixotes de feira para fazer as carteiras com que equipou uma sala do Centro Espírita, convertida em minúscula sala de aula para os dias de chuva. Nos dias de sol as aulas continuavam sendo ministradas no terreiro. Assim Diana seguiu por um ano, passando longos períodos no Cangume, sem condições de retornar à cidade e se comunicando com a Secretaria de Educação por meio de bilhetes enviados pelos fazendeiros vizinhos. "Depois de um ano, de uma turma de 42 
crianças, eu consegui fazer uma promissão de 17 crianças. Pra mim foi uma vitória" (DIANA).

Ainda que o entrevistador estivesse interessado em informações sobre o passado do Cangume, Diana não podia furtar-se de fazer com que o relato fosse sobre o tanto de heróico que havia em sua jornada de um ano ao sertão. Daí que a maior parte de sua narrativa não seja sobre o que ela viu e enfrentou, mas sobre as expectativas criadas em torno do que ela veria e enfrentaria. Daí, também, que boa parte do relato se dê de forma indireta, pela boca do senhor Sérgio, personagem que anuncia a jornada, seus riscos e recompensas. Daí, finalmente, que a narrativa sobre o Cangume tivesse que surgir como uma narrativa no interior de outra narrativa, na qual novamente a imagem do Cangume, mais que o próprio Cangume, foi capaz de emocionar suas detratoras (como Sherazade foi capaz de encantar o tirano), justificando seu privilégio diante das jovens professoras que a recriminavam:

E quando eu contei essa história pras professoras, eu olhava pra cara delas assim e via algumas chorando. Por isso tudo que passou na minha vida, isso tudo que eu passei no Cangume, que deve até ter um histórico meu lá, que quando eu não estiver mais aqui talvez vão lembrar de mim, quem sabe alguém vai lembrar de mim, do tempo que eu estava lá no Cangume e foi o maior sofrimento da minha vida. (DIANA).

Infelizmente, porém, não há memória clara da professora Diana entre os moradores do Cangume que têm idade para terem sido seus alunos. Ela é apenas um nome de uma longa lista de professores que chegavam e saíam do Cangume a cada ano. Antes de seu nome há outros, até mais importantes, como os dos primeiros professores voluntários que ministraram aulas para os adultos, vinculados ao Centro Espírita. Depois do seu nome também há outros mais relevantes, como o de um ex-professor que em 2003 ocupava uma secretaria municipal tão estratégica para o grupo quanto o grupo o é para ela.

\section{3.}

A escola municipal de Itaóca tem uma longa, ainda que fragmentada, história de interesse pelo bairro do Cangume. Depoimentos de alguns ex-alunos apontam que pelo menos desde o final da década de 1980, uma de suas professoras, Tereza (pseudônimo), organizava campanhas de doação de alimentos e agasalhos entre seus alunos para serem doados especificamente ao Cangume, sem incluir outros possíveis bairros carentes. Sob o pretexto de entregarem as doações, aquela professora chegou a realizar algumas visitas de alunos ao bairro, como parte de suas atividades didáticas. Segundo esses ex-alunos, o interesse da professora Tereza passava pela gravidade da pobreza do bairro e pelo fato de "todo mundo sempre dizer que ali era um quilombo".

Por um feliz incidente, pude assistir a uma fita de vídeo que trazia trechos de uma feira de ciências do segundo grau da escola municipal de Itaóca do ano de 1998, na qual um dos trabalhos era dedicado justamente ao bairro do Cangume. No mural relativo ao tema, em meio a diversas fotos antigas, objetos artesanais coletados no bairro e antigas peças de ferro musealizadas de improviso, era possível ler o seguinte texto:

Pinheiro Alto. Bairro popularmente conhecido como Cangume, situa-se a $8 \mathrm{~km}$ de Itaóca e é o mais distante da cidade. Considerado como bairro subdesenvolvido, é habitado por pessoas da raça negra que há anos refugiaram-se para aquela localidade, formando, assim, um quilombo.

Há entre aquela primeira narrativa da professora Diana e essas caracterizações posteriores uma significativa passagem do épico ao filantrópico, do selvagem ao miserável e do bugre ao quilombola, de uma forma em que o desprezo se converte em curiosidade, mas sem que tal curiosidade se desvincule de uma modalidade de primitivismo. Tal passagem e variação revela também como essa função de alteridade é prenhe de ambiguidades: o Cangume passa a ser objeto de práticas simbólicas que se distribuem pelos planos político, religioso, econômico e cultural.

Os moradores do Cangume lembram que em meados da década de 1980 uma senhora de Itapetininga passou a visitar o bairro, recorrendo aos serviços do seu centro espírita e fazendo pequenas doações aos seus moradores. Em determinado momento esta senhora se engajou na organização de uma grande doação de alimentos e roupas para a comunidade, momento que continua vívido na 
memória dos moradores, justamente por explicitar a relação entre caridade e política. Essa senhora teria pedido diretamente ao senhor Francisco e dona Jandira, que sempre a hospedavam (assim como me hospedaram), que preparassem a comunidade para a chegada de um caminhão de doações. Como era época de eleições municipais, ela insistiu muito para que eles não permitissem que, no dia marcado para a chegada do caminhão, se organizasse qualquer tipo comício ou manifestação política no bairro. Nas palavras de Francisco e Jandira, ela não queria que a caridade se misturasse com a política. Apesar disso, a notícia sobre a doação se espalhou e, no dia previsto, o Cangume estava repleto de políticos e cabos-eleitorais, sem que eles pudessem fazer nada com relação a isso. A confusão foi grande, com os cabos-eleitorais se interpondo entre o caminhão e os moradores e, à revelia da autora da caridade, organizando a distribuição das roupas e alimentos. Segundo Francisco e Jandira, essa senhora teria ficado tão decepcionada que nunca mais retornou ao bairro. ${ }^{5}$

\section{4.}

Como vimos, o interesse da professora Tereza, que em finais dos anos 1980 organizava visitas pedagógico-humanitárias ao Cangume, passava não só pela gravidade de sua pobreza, mas também pelo fato de "todo mundo sempre dizer que ali era um quilombo". Isso nos leva ao tema da produção do consenso em torno da origem quilombola do bairro, que em fins da década de 1990 parecia estar perfeitamente estabelecido na região.

Se recorrermos ao trabalho de um conhecido historiador autodidata local sobre a história de Apiaí (MANCEBO, 2001), veremos que o autor, depois de fazer referência ao papel desempenhado nessa fundação pela mineração aurífera, fala sobre os "tipos humanos" que contribuíram para a formação daquela população, citando sucessivamente

5 Outros exemplos confirmam a importância e frequência de tais visitas de caridade. Quase todos os finais de ano um grupo de funcionários de uma grande empresa mineradora instalada no município vizinho visita o Cangume para entregar doações de natal. Por outro lado, a rede de contatos aberta com as migrações de cangumeiros para o município de Tatuí abriu novos fluxos de caridade. Um casal conhecido dessa rede passou vários anos visitando o bairro, trazendo "um caminhão" de cestas básicas para todos os moradores. os "faiscadores", os "índios" e, finalmente, os "negros". Sobre esses últimos afirma:

As fugas aos poucos desarvoraram os senhores e o garimpo. Espalhados se escondem os negros pelo mais denso da mata, e apesar disso não se tem notícia de refúgios fortificados, mas a dispersão favoreceu formarem sítios como os do Cangume, do Calaboço, Sumidor, e mesmo do Quilombo entre a vila e Pinheiros, não se conhecendo deste último a verdadeira origem; senão também por suposições, nem mesmo sobre a existência de líder revolucionário mas sim de alguns apegados às crendices e ao misticismo próprio dos seus ancestrais. (MANCEBO, 2001, p. 21).

Mais adiante, o autor arrisca uma hipótese histórica sobre a origem do Cangume:

A comunidade negra rural que prevaleceu é a do Cangume, situada nas imediações de Itaóca. A suposta relação entre as fugas e a sua existência firma-se pela dedução de fatos que se ligam entre si, que sugerem. Supostamente, relaciona-se pela dedução de fatos afins e às fugas do garimpo. Não Há documento que comprove, porém tudo é possível diante de certas evidências. Primeiro, o acesso quase impraticável ao lugar, na ocasião, o que pode sugerir esconderijos, levando em conta o difícil acesso a morro de altitude elevada. Segundo, e mais interessante, o que se pode chamar de posto avançado de vigia: Antes da vila de Cangume existe o sítio denominado Henrique, nome cuja história, nenhum morador consegue atualmente explicar. Ora, folhando-se a história, depara-se com relatos sobre fortalezas de quilombos vigiadas por milícias negras, as quais se chamavam Henriques, uma espécie de guarda real, em homenagem ao herói que em 1648 comandou a luta pela restauração de Pernambuco, o negro Henrique Dias. Um quilombo com vigias permanentes, esta teria sido a origem do Cangume. (MANCEBO, 2001, p. 167).

O interesse no trabalho de Mancebo (2001) está no fato dele pautar-se largamente na coleta e transcrição de fragmentos da memória da elite local e de personagens populares conhecidos. É com base nisso que ele se permite afirmar, mesmo que sem apoio documental, uma relação entre os povoados de negros citados (entre eles o Cangume) e as fugas de escravos que "desarvoraram os senhores e o garimpo" e povoaram as matas em torno da vila. Essa é uma dedução que parece lógica para a sociedade local por vários motivos, todos indiciais. 
Primeiro pelo contraste de cor entre os cangumeiros e os moradores dos bairros vizinhos. Segundo em razão do desconhecimento sobre a origem precisa do bairro, também em contraste com os bairros vizinhos, todos formados por famílias paulistas tradicionais na região, algumas vindas de Portugal, e uma grande parcela de migradas de Minas Gerais e Paraná. Terceiro em razão do "isolamento" (permanentemente reificado) que marca a comunidade. $\mathrm{E}$, finalmente, pelo partilhamento de um senso comum histórico que reconhece a prática da fuga de escravos das minas de Morro do Ouro para as matas do antigo município de Apiaí.

\section{5.}

A experiência escolar levou um dos ex-alunos da escola municipal de Itaóca, sensibilizado pelas visitas promovidas pela professora Tereza, a propor a primeira pesquisa universitária que teve especificamente o Cangume como objeto de interesse. O sucinto relatório final da pesquisa desenvolvida por um grupo de alunos de graduação em ciências sociais da Unesp, intitulado Cangume: raizes e história: um estudo de uma comunidade negra rural no Alto Vale do Ribeira, 1997-1998 (FARIA et al, 1998), ${ }^{6}$ destaca algumas das características do bairro, recorrentes nos poucos textos disponíveis: a apropriação coletiva da terra, ainda que com a produção individualizada; a agricultura rudimentar e de subsistência, que marca uma pobreza generalizada; o predomínio da endogamia, ao se fazer referência ao privilégio dado ao casamento entre primos; o passado de invasão das terras da comunidade por fazendeiros vizinhos; e a conversão de todo o grupo à religião kardecista desde os anos de 1920.

O maior destaque do relatório, porém, era uma série de faltas que caracterizariam o grupo e, de certa forma, poderiam descaracterizá-lo como remanescentes de quilombos. Essas faltas tinham por referência um determinado modelo de como deveria ser e se organizar uma comunidade negra rural e, em especial, uma comunidade remanes-

6 Agradeço a Vidal Dias da Mota Júnior a indicação desse trabalho, desenvolvido pelos bolsistas de graduação da Faculdade de Ciências Sociais da Unesp sob orientação do professor Dagoberto José Fonseca. cente de quilombos, ao qual o Cangume frustrava. Faremos uma referência muito rápida a elas, por apontarem para uma espécie de senso comum acadêmico criado em torno da temática.

A primeira delas era a falta de "uma trama mítica que desse condições dela estruturar um território comum a partir de um parente comum, ou seja, um mesmo 'pai fundador' que edificasse uma solidariedade e uma identidade coletivas". (FARIA et al, 1998, p. 5).A segunda falta era relativa às "práticas de cura, de prevenção às doenças e as de cuidar de partos como poderia se acreditar, posto que estamos diante de uma comunidade afro-brasileira remanescente de quilombo estabelecida longe da cidade de Itaóca" (FARIA et al, 1998, p. 8). Finalmente, talvez a mais importante falta se manifestava no "silêncio em relação aos supostos 'resíduos culturais' da África. Eles não lembram nada, ou melhor, desconhecem os assuntos vinculados a esse "continente pai'", assim como "não têm em sua origem comunitária e, mesmo mítica, qualquer vínculo com a escravidão, posto que nasceram livres" (FARIA et al, 1998, p. 8-9). Tais faltas colocariam em risco, segundo os jovens autores, a caracterização do Cangume como remanescente de quilombo.

Aqui valem dois breves apontamentos sobre como essa situação específica é boa para pensar a relação complexa que os trabalhos acadêmicos (mesmo uma modesta pesquisa de graduação) mantêm com a realidade.

Primeiro, um apontamento sobre como as teorias (ou, mais simplesmente, os pressupostos) podem resistir às evidências. Por meio das faltas relacionadas acima, os jovens estudantes reproduziam, com relação ao Cangume, o mesmo disgnóstico que Renato Queiroz, quinze anos antes, havia produzido com relação ao bairro de Ivaporunduva: "não havia vestígios aparentes de traços de cultura africana [...] a não ser aqueles que, juntamente com os de origem indígena e portuguesa [...] integram o que se convencionou chamar de 'cultura caipira' [...] Os negros eram, assim, caipiras" "Q (QUEIROZ, 1983, p. 24). No ano de 1998, entretanto, Ivaporunduva já era uma das comunidades quilombolas mais reconhecidas e mobilizadas do Vale do Ribei-

7 E não "africanos" - poderíamos completar a frase. 
ra, tendo um importante papel na mobilização das demais. A relação pressuposta entre traços culturais e identificação como comunidade quilombola havia sido transformada radicalmente entre 1983 e 1998.

Segundo, um apontamento sobre como as descrições do mundo interferem sobre o próprio mundo, embaralhando a distinção cartesiana entre sujeiro e objeto. Conforme a avaliação de uma das alunas envolvidas na pesquisa da Unesp, o seu trabalho de graduação pode ter tido influência sobre a visibilidade regional do Cangume e, por isso, alguma interferência no curso do seu reconhecimento como remanescente de quilombos, apesar do que o próprio relatório dizia, em razão do citado diagnóstico das faltas. Isto porque, segundo esta estudante, é bem provável que tenha sido a publicação no jornal “Apiaí Diz", em 2001, de uma matéria baseada naquela pesquisa, que teria alertado as lideranças quilombolas da região, reunidas naquele mesmo momento em um encontro quilombola em Registro, para a existência do Cangume. Logo depois a comunidade seria procurada para se integrar à rede de comunidades do Vale do Ribeira que buscam a regularização de suas posses por meio da aplicação do artigo 68 (ADCT).

Assim, podemos tirar desse simples exemplo três desdobramentos importantes do tal embaralhamento entre pressupostos e evidências, sujeitos e objetos: as classificações acadêmicas (ou científicas) não estão fora do mundo, mas fazem parte dele, sendo portanto históricas; toda produção intelectual é política, por mais que não se pense assim, na medida em que ela interfere sobre o mundo descrito; finalmente, toda descrição que insiste em uma caracterização estática do mundo, como aquelas assentadas no culturalismo, erra ao não reconhecer a capacidade dos agentes refletirem, interpretarem e agirem sobre sua própria cultura.

\section{6.}

Apesar do receio dos jovens estudantes, o senso comum em torno do caráter quilombola do Cangume tornou-se tão sólido que penetrou na própria administração pública, não apenas como um projeto de reconhecimento oficial do grupo, mas como a certeza de que o grupo já teria sido oficialmente reconhecido, segundo outros secretários, menos envolvidos naquele projeto. ${ }^{8} \mathrm{O}$ motivo dessa certeza está no retorno favorável que a política social do município tem encontrado ao enfatizar as ações no Cangume, classificando-o, para todos os efeitos, como remanescente de quilombo.

Um jovem ex-professor do bairro, que se destacou na promoção de campanhas de caridade dirigidas ao grupo, acabou por ser convidado a integrar o governo municipal, como secretário de Ação Social. Com isso, o Cangume passou a se destacar frente às políticas de assistência social do município, ainda que, diante da precariedade das condições de vida do bairro e da escassez de recursos de Itaóca, isso não tenha significado uma alteração substantiva nas condições de vida dos cangumeiros.

Segundo o depoimento do secretário de educação do município, ${ }^{9}$ até 1997 a comunidade estava praticamente isolada e foi a partir deste ano que a municipalidade construiu a escola de alvenaria da comunidade e estabeleceu um transporte público diário ligando Itaóca ao Cangume, para atender os alunos que estivessem entrando no segundo ciclo do ensino fundamental, mas que passa a servir, finalmente, a toda a comunidade.

Finalmente, em 2000, o projeto de construção de casas populares da prefeitura, intitulado "Habitação para a Comunidade remanescente do quilombo do Cangume" concorreu e foi premiado no concurso "Melhores Práticas e Programas de Liderança Local" da Conferência das Nações Unidas para Assentamentos Humanos. ${ }^{10}$ No texto de apresentação do projeto a prefeitura informava que

O Bairro do Cangume, localizado no município de Itaoca, abriga a comunidade negra, oriunda de um quilombo do século 18 e que ainda preserva suas ra-

8 Em uma das rápidas conversas que tive com funcionários da Prefeitura, um desses secretários surpreendeu-se quando eu contei os objetivos do trabalho que estava realizando, destinado ao reconhecimento oficial do grupo como comunidade remanescente de quilombos. Ao contrário disso, ele me afirmava com absoluta segurança que o grupo já era oficialmente reconhecido e chegou a procurar uma cópia do Diário Oficial que pensava ter guardado com o ato de reconhecimento do governador Mário Covas, sem que pudesse encontrá-la.

9 Depoimento oral concedido em 2003.

10 O Programa das Nações Unidas, em parceria com a Caixa Econômica Federal e com o Instituto Brasileiro de Administração Municipal, concedeu no dia 23.02.2000 o prêmio "Caixa Melhores Práticas" a dez programas habitacionais, de infraestrutura e geração de emprego e renda, selecionados entre 114 de todo o país, representantes de 18 estados, com envolvimento direto de 42 Escritórios de Negócios da Caixa. 
ízes, costumes e religiosidade. [...] Habitavam casas de pau-a-pique e barro, cobertas de sapé, a maioria sem unidades sanitárias, sem saneamento básico, água tratada ou energia elétrica. Apresentavam alto índice de mortalidade infantil (80 para cada 1.000 nascidos vivos), analfabetismo e pobreza extrema, vivendo inteiramente isolados da cidade. (CAIXA ECONÔMICA FEDERAL, 2001).

Assim, o interesse escolar, o senso comum histórico local, as práticas caritativas e a política fechavam um circuito em torno do bairro do Cangume, fixando o seu lugar de comunidade quilombola e orientando as políticas públicas, mesmo antes do seu reconhecimento oficial.

\section{7.}

Para entender a a formação desse circuito fechado em torno do Cangume, entretanto, é importante mudar a escala de nossa observação e registrar que a década de 1980 viveu a "descoberta" política e científica das comunidades ou bairros negros rurais do interior paulista. ${ }^{11}$ Nas palavras de João Batista Borges Pereira, professor e pesquisador da USP diretamente envolvido nessas descobertas, elas alimentavam a "efervescência intelectual ligada à construção de toda uma ideologia de auto-afirmação racial nucleada na idéia de quilombo" (PEREIRA, 1983).

Depois da "descoberta" do Cafundó em 1978, foi organizada uma primeira expedição ao Vale do Ribeira, especificamente à região de Iporanga, em busca de novas comunidades que "conservassem também vestígios de línguas "exóticas"” (VOGT; FRY, 1996, p. 211). Apesar da frustração dessa primeira iniciativa, seguem-se outras que dariam origem às primeiras pesquisas linguísticas sobre as comunidades do Vale do Ribeira. Tais expedições novamente são orientadas por indicações de professoras das escolas municipais da região e alimentam o interesse da imprensa pelo tema, assim como são incrementadas por ele. ${ }^{12}$ É nesse contexto

11 Vogt e Fry (1996), ao reconstituírem o trajeto de sua pesquisa no Cafundó (Salto do Pirapora - SP) nos oferecem um vivo retrato dessa "descoberta", assim como uma fina reflexão sobre suas implicações políticas e acadêmicas.

12 A importância da imprensa nessas "descobertas" acadêmicas entre o fim da década de 1970 e ao longo da década de 1980 está registrada em Vogt e Fry (1996) e Careno (1997). que surgem as primeiras menções ao Cangume na imprensa, visitado pela primeira vez por interesses acadêmicos em 1987 (CARENO, 1997, p. 13-14).

Tudo isso começou a jogar uma nova luz sobre aquele bairro rural de negros, fazendo com que até mesmo as visitas de caridade ganhassem uma nova dimensão. Não é casual, portanto, que tenha sido em 1993, ano da emancipação do município de Itaóca, que o interesse pelo Cangume tenha ultrapassado o circuito regional para ganhar espaço na imprensa estadual: uma reportagem, que ocupou duas páginas inteiras da edição de domingo (07.02.1993) do Correio Popular de Campinas (VILA..., 1993) e que trazia o cabeçalho geral "Vila de Negros". Nela eram estampados dois títulos principais: "Cangume vive rotina do século passado" e "TV a bateria liga 'aldeia' ao mundo moderno". A grande ênfase da reportagem estava no isolamento do bairro e nas suas formas arcaicas. Em um dos seus destaques (olho), a reportagem informava: "Isolados no sul do Estado, 122 pessoas se sustentam na roça e preservam costumes", enquanto outro adiantava uma explicação: "Os fundadores da vila eram escravos fugitivos. Por isso, falavam pouco sobre suas origens aos descendentes".

A matéria descreve os hábitos alimentares de seus moradores, seu nível de renda, o artesanato produzido, os casamentos entre primos e algumas das expressões que, citando informações da professora Mary F. Careno, apontariam para africanismos de linguagem. Entretanto a ênfase que dominava e justificava a própria reportagem estava no isolamento do bairro. Ele era medido pela distância em quilômetros de estradas de asfalto e de terra entre Campinas e Itaóca $(337 \mathrm{~km})$ e depois entre Itaóca e Cangume $(11 \mathrm{~km})$, mas também pela ignorância dos seus moradores com relação aos temas ou expressões dominantes na mídia daquele momento, pelo medo que alguns de seus moradores teriam dos estranhos ou mesmo por uma espécie de suspensão do calendário - "o tempo parado há mais de um século no Cangume" - cuja referência fundamental seria o ciclo agrícola. Enfim, uma descrição que faz com que o leitor se veja defrontado com uma realidade outra, distante no tempo e no espaço, primitiva. 
Apesar da recorrência de imagens que fazem com que o texto da reportagem de 1993 se aproxime tanto do relato da professora Diana sobre o bairro, de trinta anos antes, ele surgia em um contexto muito distinto, que articulava sentidos opostos. A emancipação do município, economicamente inexpressivo e carente de outros atrativos, deu, de uma forma imprevista, nova visibilidade ao Cangume.

\section{8.}

Essa visibilidade seria reforçada por uma pesquisa que viria na esteira da descoberta dos bairros negros paulistas sob o ponto de vista linguistico. Ainda que não tenha sido diretamente abordado na análise de Mary F. Careno sobre a linguagem falada em comunidades negras rurais do Vale do Ribeira (finalizada em 1992), o Cangume foi citado entre aquelas comunidades nas quais se deveria investigar a hipótese da existência de "resquícios de uma antiga língua africana, utilizada pelos primeiros negros que habitaram a região", com o objetivo "urgente [de] resgatar a cultura africana que ainda subjaz nessas localidades" (CARENO, 1997, p. 13-14).

$\mathrm{O}$ ponto de partida da pesquisa era o quadro atual de "profundas diferenças entre o português popular do Brasil e o português padrão", no qual são encontrados traços típicos de línguas crioulas. Sempre relacionado com uma história de contato linguístico entre diferentes povos, "o crioulo surge em comunidades bilíngües ou multilíngües e, quase sempre em ilhas ou em regiões isoladas, critério conhecido como insularidade" (CARENO, 1997, p. 62). Assim, mais uma vez, o tema do isolamento retorna, caracterizando o Vale do Ribeira como a região ideal para o surgimento de um crioulo que teria por base uma língua geral corrente entre os escravos - o quimbundo. Os resultados da pesquisa, porém, não confirmaram essa hipótese. Careno (1997, p. 64) admite que o que "permanece [na região é] a estrutura do falar caipira", mas sugere que a aparente baixa frequência de termos africanos seria explicada não pela desimportância dos africanismos, mas por sua profundidade e extensão. O número de empréstimos lexicais do banto ao português falado no Brasil seria tão expressivo e ele estaria tão integrado ao sistema linguístico que formaria derivados portugueses a partir de uma mesma raiz banto. Isso lhe permite reformular a hipótese para propor que

Essa estrutura primeira, com abundância de termos africanos, ainda nos tempos atuais é encontrada em algumas localidades brasileiras, cujos habitantes são essencialmente negros. Estudos revelam que essa língua é um remanescente do quimbundo e é falada somente em ocasiões especiais. Exemplos dela foram descobertos em algumas comunidades rurais. (CARENO, 1997, p. 64).

É desse referencial que parte a pesquisa que Margarida M. T. Petter (2001) iniciou no Cangume, na qual procura "traços fonéticos específicos" na fala dos mais velhos, que revelem a existência de "africanismos". Segundo esta autora, entre as quatro formas de criação de "brasileirismos", está o contato com outras línguas e, por meio desses contatos, a constituição de linguagens de mediação, linguagens mestiças ou crioulas, que no Brasil são conhecidas como "tupinismos" e "africanismos". ${ }^{13}$

A pesquisa de Petter (2001) aponta a existência de diferenças com relação à coleta realizada por Careno nas outras comunidades estudadas no Vale do Ribeira. No Cangume, Petter encontrou "africadas palatais" que ainda não haviam sido registradas na região e que aproximam o falar do Cangume àquele registrado nas zonas caipiras do Mato Grosso, Cuiabá e litoral do Paraná, tais como "catchorro", "petche" e "rantcho".

Petter (2001) aponta, porém, que tais ocorrências de "africadas" só foram plenamente observadas na fala dos mais velhos, assumindo uma forma transitiva nos informantes adultos entre 40 e 60 anos e desaparecendo entre os mais novos, o que aponta para uma rápida mudança linguística. Depois de todo o esforço da professora Diana, finalmente, a África que ela não tinha condições de identificar na língua daqueles negros bugres e que lhe parecia pura falta de cultura se esvai com o tempo num ritmo acelerado.

13 "Africanismo é o termo ou expressão de uso coloquial resultante do contato do português com uma língua africana, ocorrido na África, em Portugal ou no Brasil, sendo nesse caso parte integrante dos brasileirismos" (PETTER, s/d). Mesmo que o português europeu tenha, antes do descobrimento do Brasil, incorporado algumas palavras africanas - alerta Petter - a pouca informação a respeito dos itens lexicais introduzidos nesse português arcaico, anterior ao tráfico de escravos para o Brasil, não permitem fazer uma distinção precisa entre os africanismos introduzidos via Portugal e aqueles vindos diretamente da África para o Brasil. 
Mesmo assim, o interesse da pesquisa linguística recente faz com que o Cangume surja entre as outras comunidades negras rurais do Vale do Ribeira como local estratégico, dado seu insulamento, para o objetivo de se resgatar a África que nos resta na língua, já que neste bairro nós encontraríamos traços que já não são encontrados nas outras comunidades do Vale. Na medida em que cresce o interesse sobre o bairro, baseado naqueles que eram os seus sinais de estigma, torna-se irrestível voltar a citar a professora Diana quando fala desta outra dimensão da alteridade do Cangume:

Era bem ignorante assim, tudo. Inclusive tem até uma passagem muito engraçada. A palavra 'já', nenhum dos alunos conseguia falar. Quando eu pus na lousa 'já, jé, ji, jô, ju', era só ‘djá, djé, djó, dju’. Isso foi até terminar o ano. Eu não consegui arrancar nenhum 'já' de nenhum deles. Nem do pai, nem da mãe. A palavra 'já' pra eles não saía, não sei. Por exemplo, não era 'pintei', era 'pintchei'. (DIANA)

A última ressignificação da alteridade do Cangume parece convertar finalmente um dos signos da sua suposta ignorância, que deveria ser eliminada, em um marcador de "cultura" a ser registrado e, talvez, preservado. Tema difícil que se impõe às escolas dedicadas a pensar em uma educação diferenciada para as comunidades quilombolas.

\section{Considerações finais}

As cenas e situações históricas descritas acima permitem esboçar o processo de transformação dos conteúdos e símbolos associados às fronteiras étnicas do Cangume. Se a fronteira lhes foi imposta historicamente, por meio da imputação de conteúdos estigmatizantes, recentemente esta mesma fronteira consensual, mas ressignificada, justifica o reconhecimento de seus direitos como uma "comunidade remanescente de quilombos". Nos últimos anos, sua língua, seu suposto isolamento e a ambiguidade das relações mantidas com base na caridade passaram a ser positivadas, convertendo a sua função de alteridade, que deixa de servir apenas à lógica classificatória dos brancos de Itaóca para servir também aos próprio cangumeiros.

Esse processo e suas clivagens são ilustrados por um relato que me foi feito por Jandira. Em um tom maternal, ela me contou uma conversa mantida com a sua filha, na qual a moça manifestava intenso desconforto ao ler a matéria de jornal citada anteriormente, na qual o Cangume era descrito como uma "vila de negros". A indignação de sua filha, uma jovem que saiu do Cangume para estudar e trabalhar em Tatuí, conquistando um emprego fixo, uma casa de alvenaria, uma linguagem "correta", enfim, livrando-se dos estigmas atribuídos aos cangumeiros, parecia perfeitamente compreensível para Jandira. Contudo também estava claro, no modo de Jandira relatar a situação, o anacronismo daquela indignação. Por morar em Tatuí, sua filha não podia experimentar as mudanças decorrentes da conversão simbólica dos estigmas atribuídos ao bairro. Jandira conta, então, como ela mesma fez sua filha perceber como aquele rótulo não só era verdadeiro, como tornara-se aceitável, na medida em que não era mais uma acusação, mas uma forma de identificação que passava a ter sua própria dignidade.

Um ano depois dessa conversa com Jandira, o ITESP reconheceria oficialmente o Cangume como uma comunidade remanescente de quilombos, com o direito sobre um território de 724,6 hectares, contra os 37 hectares que vinha ocupando desde a década de 1960. Depois disso a luta da comunidade por seu território original ganhou fôlego e, em 2010, a sua Associação conseguiu a reintegração de posse de duas áreas vizinhas, permitindo que as suas famílias passassem a dispor, efetivamente, de 166,9 hectares (INSTITUTO SOCIOAMBIENTAL, 2010). A comunidade continua fora da posse da maior parte de seu território, mas os termos da disputa mudaram bastante. Para ficarmos com um exemplo importante disso, em 2013 o Cangume foi relacionado no Inventário Cultural de Quilombos do Vale do Ribeira, produzido pelo Instituto Socioambiental, com base na metodologia do Inventário Nacional de Referências Culturais do Iphan (ANDRADE; TATTO, 2013). Ao lado de outras 15 comunidades, o Cangume tem parte de suas celebrações, formas de expressão, oficios e modos de fazer, lugares e edificações reconhecidas como patrimônio cultural, como parte de um processo mais largo de ressignificação da alteridade dessas comunidades na região e no país.

Neste texto descrevemos este processo de ressignificação desde sua dinâmica local, investigando o papel nela desempenhado por agentes, 
saberes e práticas escolares. Não exploramos tanto a perspectiva dos cangumeiros quanto a sua função de alteridade para a sociedade do seu entorno. Pensado como um espaço dedicado à transmissão da Cultura, à passagem do iletrado ao letrado, do mundo infantil (primitivo) ao adulto (civilizado), a escola atuou na reelaboração da função de alteridade do Cangume, mas não pode ser pensada como imune a esta mesma reelaboração. Todo este processo reverbera de forma crítica sobre a própria imagem da escola no seu sentido clássico, abrindo um grande campo de indagações. Como as escolas, seus agentes e suas práticas devem (re) pensar as fronteiras simbólicas que a sua simples presença ajuda a construir? Como o reconhecimento da legitimidade dos modos de ser dessas comunidades, que acompanha o reconhecimento da legitimidade dos seus territórios, incide sobre as hierarquias de saber e de cultura que a escola ajuda a naturalizar, mais do que a discutir? Como a escola está se preparando para enfrentar tais perguntas cada dia mais inevitáveis?

\section{REFERÊNCIAS}

ANDRADE, Anna Maria; TATTO, Nilto (Ed.). Inventário cultural de quilombos do Vale do Ribeira. São Paulo: Instituto Socioambiental, 2013.

ARRUTI, José Maurício. Uso comum, regularização fundiária e mercado de terras - estudo de caso no Cangume (Vale do Ribeira / SP). In: LEITE, Renata; MELO, Paulo (Org.). Prêmio Territórios Quilombolas 2a edição. Brasília, DF: MDA/NEAD, 2007. p. 230-269.

BARTH, Fredrik. Introducción. En: (Org.). Los grupos étnicos y sus fronteras - La organización de las diferencias culturales. México: Fundo de Cultura Econômica, 1976.

CAIXA ECONÔMICA FEDERAL. Prêmio CAIXA Melhores Práticas em Gestão Local 1999/2000. Práticas premiadas. Itaóca. Brasília, DF, 2001. Disponível em: <http://www.caixa.gov.br/sustentabilidade/responsabilidade-social/melhores-praticas/edicao-1999-2000/Paginas/default.aspx>. Acesso em: 09 ago. 2017.

CARDOSO DE OLIVEIRA, Roberto. Identidade, etnia e estrutura social. São Paulo: Pioneira, 1976.

CARENO, Mary Francisca do. Vale do Ribeira - a voz e a vez das comunidades negras. São Paulo: Arte e Ciência/ UNIP, 1997. (Coleção Universidade Aberta, v. 27).

FARIA, Alessandra M. Et al. Cangume: raízes e história: um estudo de uma comunidade negra e rural no Alto Vale do Ribeira. 1998. Monografia (Graduação em Ciências Sociais) - Universidade Estadual Paulista (UNESP), Araraquara, SP, 1998.

INSTITUTO BRASILEIRO DE GEOGRAFIA E ESTATÍSTICA(IBGE). Cidades: Itaóca. Disponível em: $<$ https:// cidades.ibge.gov.br/v4/brasil/sp/itaoca/panorama>. Acesso em: 30 jul. 2017.

INSTITUTO SOCIOAMBIENTAL. Comunidade do Cangume consegue reintegração de posse e garante sua sobrevivência. Altamira, PA, 2010. Disponível em: <https://site-antigo.socioambiental.org/nsa/detalhe?id=3239>. Acesso em: 30 jul. 2017.

MANCEBO, Oswaldo. Apiaí: do sertão à civilização - história regional, Apiaí no Alto Ribeira e arredores. São Paulo: Omega, 2001.

PEREIRA, João B. Borges. Prefácio. In: QUEIROZ, Renato. Caipiras negros no Vale do Ribeira: um estudo de antropologia econômica. São Paulo: FFLCH-USP, 1983. p. 17-19.

PETTER, Margarida Maria Taddoni. A fala da comunidade do Cangume: alguns traços fonéticos específicos. São Paulo, 2001. (mimeo).

QUEIROZ, Renato. Caipiras negros no Vale do Ribeira: um estudo de antropologia econômica. São Paulo: FFLCH-USP, 1983.

VILA dos negros. Correio Popular de Campinas, Campinas, SP, 07 fev. 1993.

VOGT, Carlos; FRY, Peter. Cafundó - a África no Brasil. São Paulo: Companhia das Letras, 1996. 